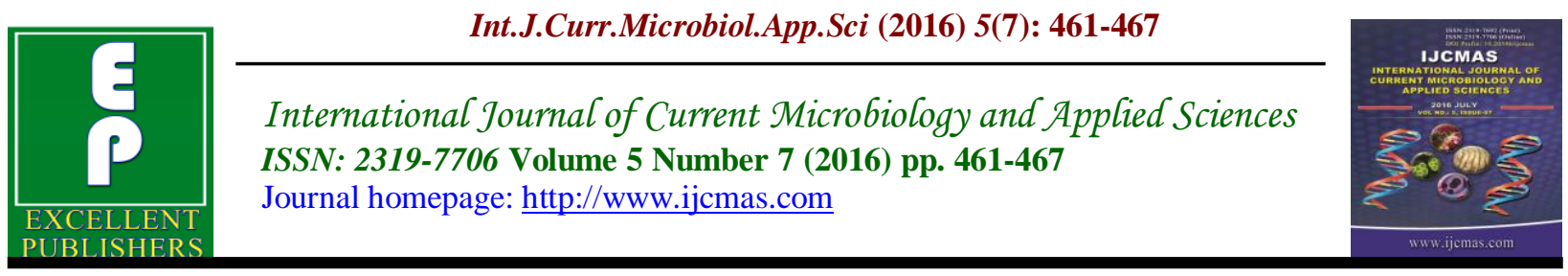

Original Research Article

http://dx.doi.org/10.20546/ijcmas.2016.507.049

\title{
Purification of Actinomycin D from Streptomyces parvulus Isolated from Mangrove Ecosystem of Kerala, India
}

\author{
R. Cibi and A. Jayakumaran Nair* \\ Department of Biotechnology, University of Kerala, Karyavattom, Trivandrum, India \\ *Corresponding author
}

\begin{abstract}
A B S T R A C T
Keywords

Streptomyces, actinomycin D, HPLC, cytotoxicity, mass spectrum.

\begin{tabular}{l}
\hline Article Info \\
\hline Accepted: \\
15 June 2016 \\
Available Online: \\
10 July 2016
\end{tabular}

The present study was conducted to purify and characterize the active compound produced from Streptomyces parvulus for evaluating its cytotoxic potential against tumor cell line. The Streptomyces parvulus CBJ1, isolated from mangrove ecosystem of Poovar found to be an efficient producer of bioactive compound. The isolate produced yellow color in ISP2 production media during submerged fermentation. The orange color compound was obtained from mycelia extract using thin layer chromatography and purity was checked using reverse phase HPLC. The purified compound was identified as actinomycin D on the basis ofultraviolet-visible spectroscopy, mass spectroscopy and by comparison with published reference compounds. Theantitumor activity of purified compound, actinomycin D analyzed on A549 cell line by MTTassay. The actinomycin D showed cytotoxicity on A549cell line depending on the dose and incubation time. It showed $77 \%$ cytotoxicity at concentration of compound $1.25 \mu \mathrm{g} / \mathrm{ml}$ with IC50 value of $0.52 \mu \mathrm{g} / \mathrm{ml}$.
\end{abstract}

\section{Introduction}

Approximately half of the devastating effects in humankind are due to infectious disease (Walsh and Warren, 1974). Cancer still remains one of the most serious health problem in both developing and developed countries. Therapeutic methods for cancer treatment has enabled us to focus on novel bioactive secondary metabolites from natural source for effective drug development. Actinomycetes are prokaryote with the highest recorded chemical diversity produce many secondary metabolites of novel chemical structures and versatile bioactivities (Watve, 200; Aroonsri et al., 2012). Among the actinomycetes genus
$50 \%$ of the soil actinomycetes are constituted by Streptomyces, provide 70$80 \%$ of secondary metabolites. Streptomyces have been reported to produce several bioactive compounds that include antibiotics, antioxidants, immunosuppressive agents and cytotoxic compounds (Newman and Cragg, 2007).

Mangrove ecosystem is called home land of microb et al., due to the presence of rich source of nutrients. This ecosystem situated between the terrestrial and marine environment which are highly productive ecosystem and abode to large unexplored 
microbial diversity (Ghosh et al., 2010). The actinomycetes diversity from mangrove ecosystems have been proven as excellent source for discovering secondary metabolites which have application medical field.The present study was designed to purify and characterize the compound produced from Streptomyces parvulus CBJ1 for investigating the cytotoxic potency against tumor cell line.

\section{Materials and Methods}

\section{Isolation}

During screening of bioactive actinomycetes, Streptomyces parvulus CBJI was isolated from the mangrove soil of Poovar $\left(8.3177^{0} \mathrm{~N}, 77.0708^{\circ} \mathrm{E}\right)$ located in Thiruvananthapuram district in Kerala, South India. The isolate was identified by morphological, phenotypic and phylogenetic data. The sequence is available in GenBank database with an accession number KT833783. The culture of isolate was grown and maintained on Yeast extract Malt extract agar (ISP2) plates (composition: D-glucose $4 \mathrm{gm} / \mathrm{L}$ malt extract $10 \mathrm{gm} / \mathrm{L}$,yeast extract $4 \mathrm{gm} / \mathrm{L}$ and agar $20 \mathrm{gm} / \mathrm{L}$ ) and stored at $4^{0} \mathrm{C}$ for further use.

\section{Fermentation and extraction of active compound}

Spores of the strain CBJI was inoculated in $100 \mathrm{ml}$ Erlenmeyer flask containing $25 \mathrm{ml}$ of ISP2 broth followed by incubation at $30^{\circ} \mathrm{C}$ on a rotary Shaker at $120 \mathrm{rpm}$ (New Brunswick) for 2 days and $\mathrm{pH}$ was adjusted to 7.5 . Subsequently, $5 \%$ of inoculum was transferred in to an $100 \mathrm{ml}$ ISP2 production media in a $250 \mathrm{ml}$ Erlenmeyer flask growing under the same above conditions for 5 days. After the incubation period the fermented broth was centrifuged at $8000 \mathrm{rpm}$ for 10 minute at $4^{\circ} \mathrm{C}$. Finally mycelium was extracted with methanol (HPLC grade, Merck) two times for 15 minutes for recovering the crude active metabolites in to methanol phase. The extracts were pooled and residual methanol was evaporated using rotary vacuum evaporator (Heidolph, Germany) at $50^{\circ} \mathrm{C}$ at $100 \mathrm{rpm}$ and vacuum $334 \mathrm{mbar}$. The crude extract was weighed and stored at $4^{\circ} \mathrm{C}$ for further analysis.

\section{Purification of active compound}

The extract was spotted on silica gel thin layer chromatography (TLC) plates, eluted using hexane:ethylacetate $(6: 4 \mathrm{v} / \mathrm{v})$ as mobile phase and retention factor of active compound was measured. The purity of active compound was checked using reverse phase HPLC (Shimadzu, USA) equipped with C18 column with 55\% acetonitrile in water as the eluting solvent both run isocratically at a flow rate of $1 \mathrm{ml} / \mathrm{min}$ for 45 minutes and retention time noted and compared with reference compound.

\section{Characterization of purified compound}

Characterization of pure active compound was carried out using different spectrometric analysis.

Theultraviolet-visible spectroscopyof active compound was taken using spectrophotometer UV- 1700 (Shimadzu, Japan).The mass spectra was recorded using JEOL JMS $600 \mathrm{H}$ mass spectrometer (JOEL, USA).

\section{Cytotoxicity assay}

The cytotoxic activity of pure compound against human tumor cell line A549(lung carcinoma) was determined by MTT (3-[4, 5-dimethylthiazol-2-yl]-2, 5-diphenyl tetrazolium bromide) assay (Wilson, 2000). Briefly $1 \times 10^{4}$ cells per well were seeded at log phase in 96 well plates. After cultivation for $24 \mathrm{hrs}$ the media was replaced with fresh 
media containing different concentration $(0.01-1.25 \mu \mathrm{g} / \mathrm{ml})$ compounds dissolved in $0.1 \%$ DMSO and treated for 24, 48 and 72 hr. After incubation at $37^{\circ} \mathrm{C}$ in $5 \% \mathrm{CO} 2$, $100 \mu 1$ of medium containing $20 \mu 1$ of MTT solution $(5 \mathrm{mg} / \mathrm{ml}$ in PBS) was added to each well and cells were incubated for $4 \mathrm{hrs}$ at $37^{\circ} \mathrm{C}$. At the end incubation, medium was removed and $100 \mu \mathrm{l}$ of DMSO was added to each well for formazan crystals to dissolve. The absorbance was measured at 570nm using Mullikan GO Micro plate Spectrophotometer (Thermoscientific). The growth inhibition was calculated from the formulae $(1-\mathrm{A} / \mathrm{B}) \times 100 \%$ where $\mathrm{A}$ and $\mathrm{B}$ corresponds to the mean absorbance of treated and control wells. The concentration of the compound that gives $50 \%$ inhibition was expressed as the $\mathrm{IC}_{50}(\mathrm{ug} / \mathrm{ml})$.

\section{Results and Discussion}

\section{Extraction and purification of compound}

The submerged fermentation of Streptomyces parvulus CBJ1 was carried out under optimum condition of $30^{\circ} \mathrm{C}$ and $120 \mathrm{rpm}$ for 5 days in a production media .The culture both was harvested on fifth day for further extraction and purification. The mycelium was separated and extracted with methanol. Organic solvents always provide a higher efficiency in extracting bioactive compounds compared to water based compounds (Masuda et al., 1997).Gyimesi et al., (1970) and Kumar et al.,(2014) have reported that methanol was used for the extraction of antimicrobial metabolites from mycelia of Streptomyces sp.

The crude extract obtained was separated by TLC using solvent system hexane:ethylceteate in the ratio 6:4 indicated the presence one distinct orange colored compound with an $\mathrm{R}_{\mathrm{f}}$ value of $0.38 \mathrm{~cm}$ Fig.1).The separated compound had UVvisible spectra at $254 \mathrm{~nm}$ and $442 \mathrm{~nm}$ in methanol similar to that of actinomycin class of compounds. The purity of yellow compound was confirmed using reverse HPLC analysis, indicating that the separated compound showed a chromatogram at $441 \mathrm{~nm}$ with an retention time of 37.656 minute similar to the pure actinomycin D purchased (Merck) (Fig.2).The results of UV-visible spectra and reverse HPLC analysis of purified compound indicates the fact that the compound have absorption maxima similar to amino phenoxazinone chromophore present in actinomycin family (Mauger and Stuart, 1990). There are examples of phenoxazinone metabolites like chandrananimycin D from Streptomyces griseus and venezueline C from Streptomyces venezuelae having anticancer activity (Gomes et al., 2010; Ren et al., 2013).

Mass spectrum of the pure compound showed the molecular ion peak at $\mathrm{m} / \mathrm{zof}$ $1255(\mathrm{M}+\mathrm{H})+$. The characterization data support the fact that the compound belongs to actinomycin D (Fig 3). Mass spectral data were compatible with actinomycin D, as recorded by Lackner et al., (2000).Around 19 species ofStreptomyces (Kurosawa et al., 2006; Praveen, 2008), Micromonospora(Wagman, 1976) and Nocardia(El-Refai, 2011)reported are capable of producing various forms of actinomycins. 
Int.J.Curr.Microbiol.App.Sci (2016) 5(7): 461-467

Fig 1. TLC Analysis of purified compound

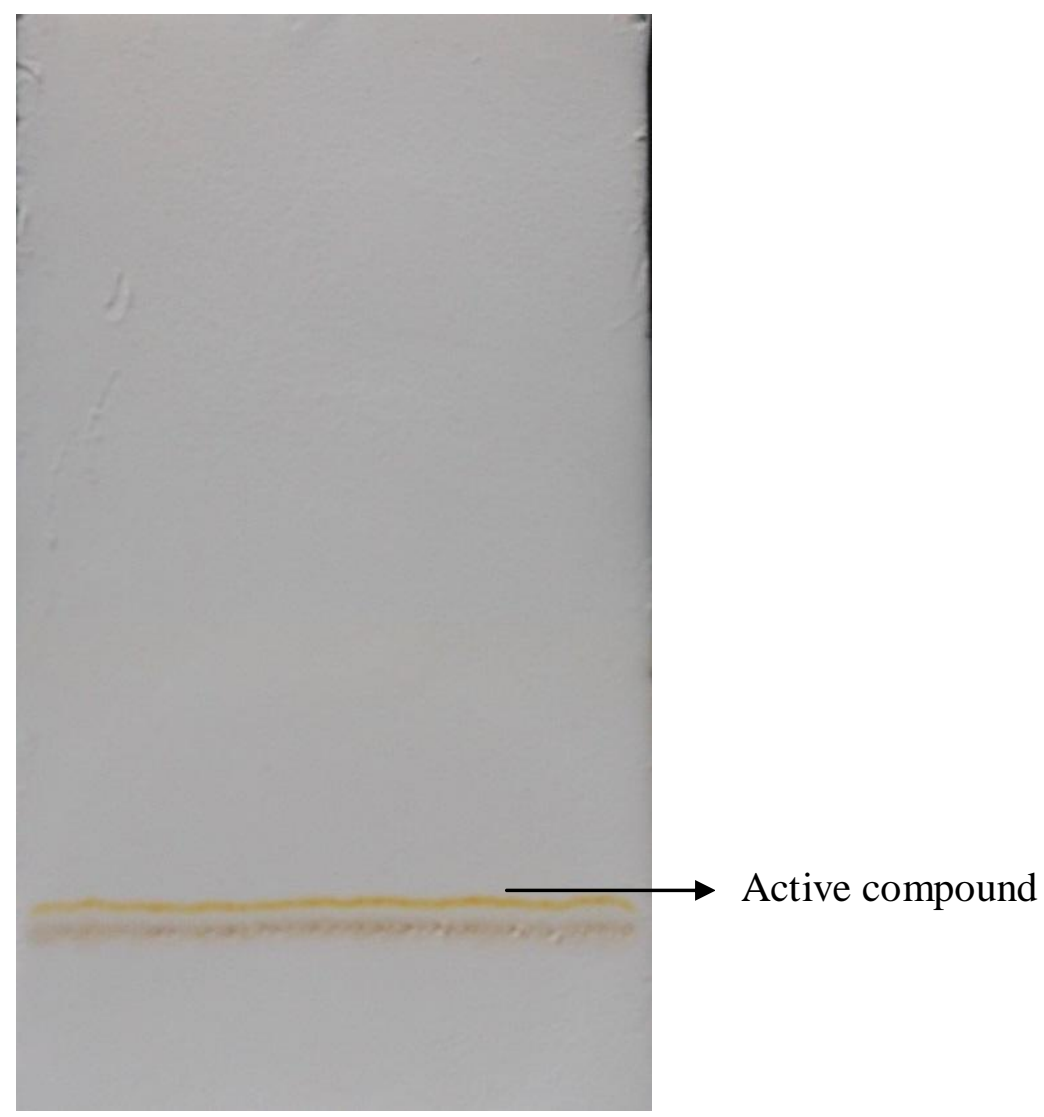


Fig. 2 HPLC analysis of purified compound

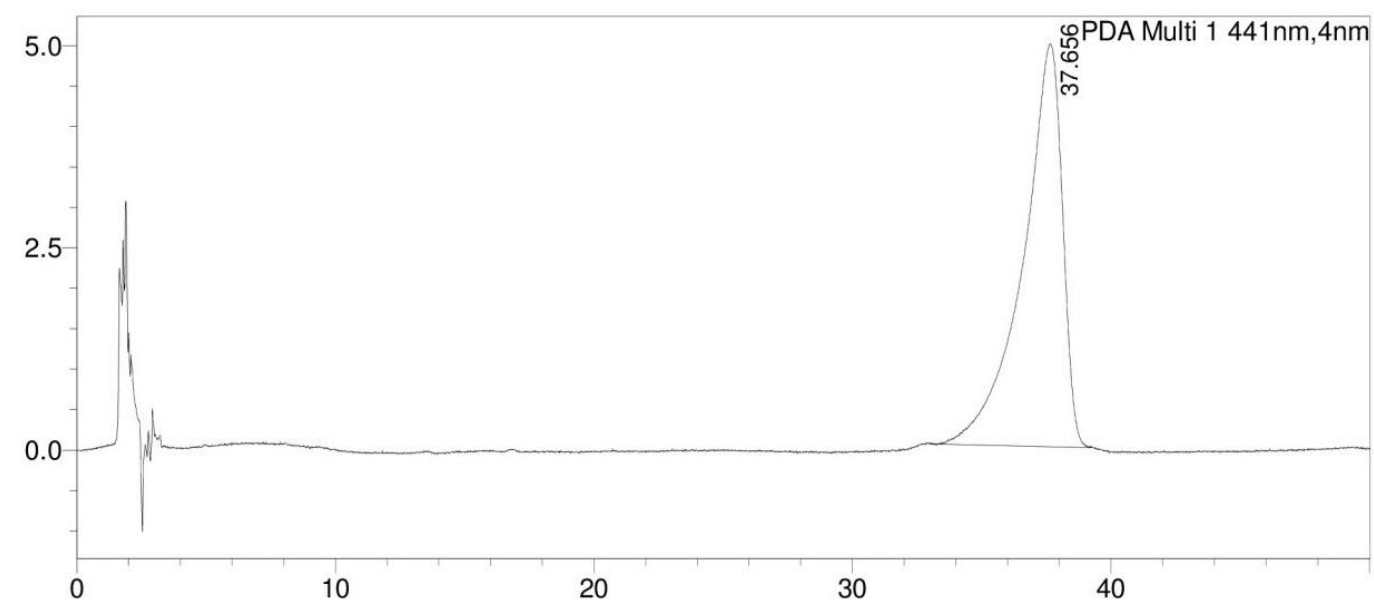

Fig.3 Mass spectrum of purified compound

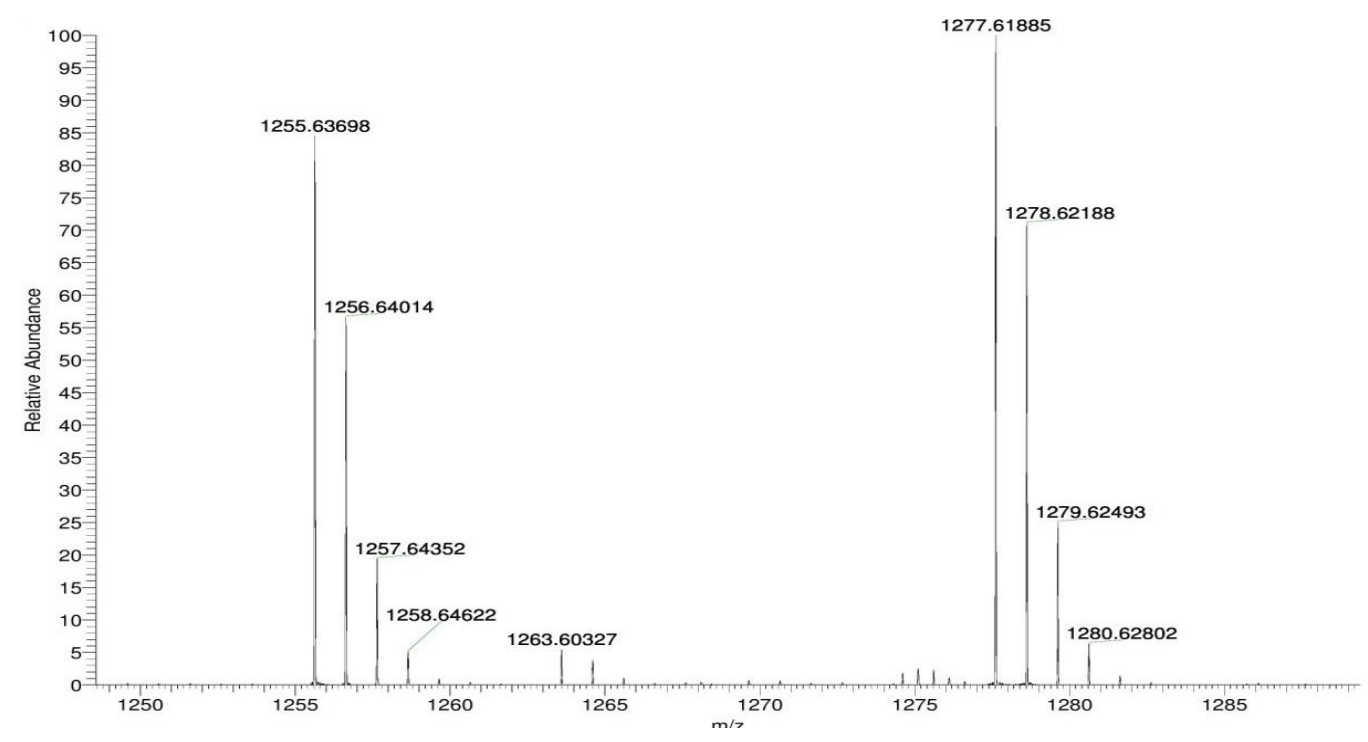

Fig.4 A549 cells treated with actinomycin D

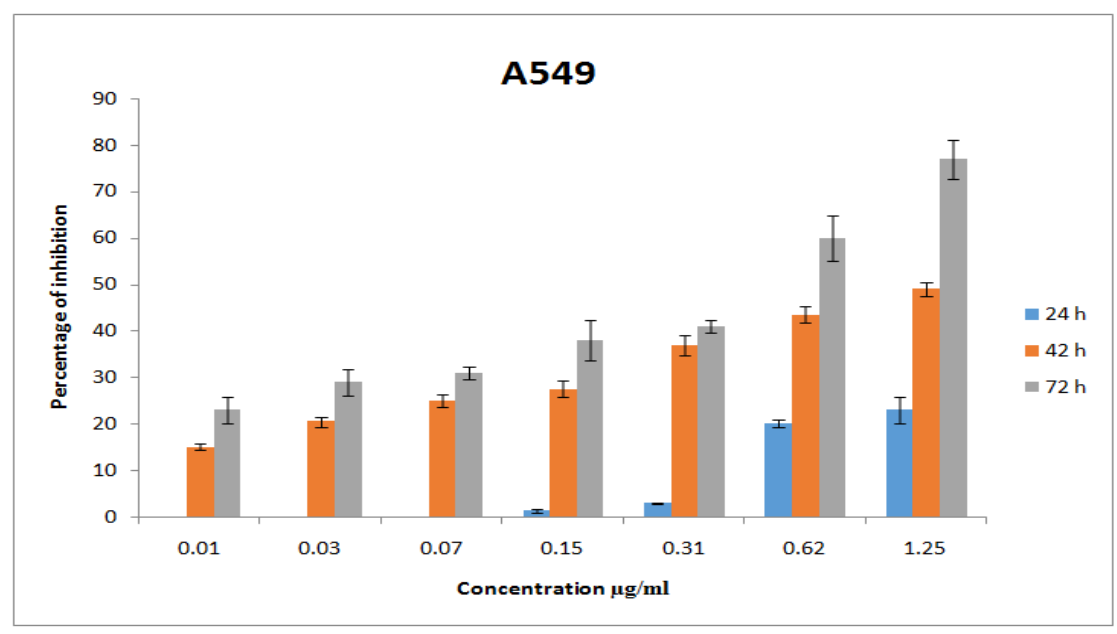




\section{Cytotoxicity assay}

To determine the cytotoxic activity of purified actinomycin D to tumor cell line, the cells were treated with increasing concentration of actinomycin D. The MTT cytotoxicity assay revealed that compound decreased the cell viability significantly $(\mathrm{P}<0.05)$ in a concentration dependent manner. As shown Fig.4 Actinomycin showed cytotoxic activity against A549 cells. It showed an IC50 of $0.52 \mu \mathrm{g} / \mathrm{ml}$ after $72 \mathrm{hrs}$ of incubation with a inhibition rate of $77 \%$ at $2.5 \mu \mathrm{g} / \mathrm{ml}$. The results agree with the previous reports that the actinomycin $\mathrm{D}$ inhibited the proliferation of pancreatic cancer cells by inducing apoptosis(Kleeff et al., 2000) .Kim et al.,(2016) recently reported that manumycin A isolated from Streptomyces parvulus have chemotherapeutic effect on malignant pleural mesothelioma.

In conclusion, the compound isolated from Streptomyces parvulus identified as actinomycin D inhibited the proliferation of tumor cells. The application of actinomycin $\mathrm{D}$ in cancer treatment enhanced the requirement for the production of this compound in large scale in future for marketing in cost effective manner.

\section{Acknowledgement}

We are thankful to the University of Kerala for the research fellowship and infrastructure provided by Department of Biotechnology, University of Kerala is also acknowledged.

\section{References}

Aroonsri, A., Kitan, S., Hashimoto, J., kosone, I., Izumikawa, M., Komatsu, M., Fujita, N., Takahashi, Y., Shin-ya, K., Ikeda. H., and Nihira, T. 2012 Pleiotropic control of secondary metabolism and morphological development by Ksbc, a butyrolactoneautoregulator homologue in Kitasatospora setae. Appl. Environ. Microbiol.,78: 8015-8024.

El-Refai, H.A., AbdElRahman, H.Y., Abdulla, H., Hanna., Ate,fG.,Hashem, A.H., El-Refai, A.H., and Ahmed, E.M. 2011. Studies on the production of actinomycin by Nocardioidesluteus, a novel Source. 5:1282-1297.

Ghosh, A., Dey, N., Bera, A., Tiwari, A., Sathyaniranjan, K., Chakrabarti, K et al. 2010. Culture independent molecular analysis of bacterial communities in the mangrove sediment of sundarban. India. AquatBiosyst., 6: 8-16.

Gomes, P.B., Nett, M., Dahse, H.M., and Hertweck, C. 2010. Pitucamycin: structural merger of a phenoxazinone with aepoxyquinone antibiotic. J. Nat. Prod., 73:1461-1464.

Gyimesi, J., Ott, I., Horvath, I., Koczka., and Magyar, K. 1970. New polyenic antibiotic oleficin exhibiting antibacterial activity. J. Antibiot., 24: 209-214.

Kleeffet al. 2000.Actinomycin D induces apoptosis and inhibits growth of pancreatic cancer cells.Int. J. Cancer, 86: 399.

Kim, K.H., Chae, J., Oh, H., Cho, J.H., Lee, R.H., Yoon, G., Cho, S.S., Cho, Y.S., Lee, M.H., Liu, k., Lee. H.J., Shim, J.H. 2016. Manumycin A induces apoptosis in malignant pleural mesothelioma through regulation of Sp1 and activation of the mitochondriarelated apoptotic pathway. 36, 117-124

Kumar, S.P., Duraipandiyan, V., and Ignacimuthu, S. 2014. Isolation, screening and partial purification ofantimicrobial antibiotics from soil Streptomyces sp. SCA 7. Keio. J. Med., 30, $435-446$. 
Kurosawa, K., Buim, V.P., VanEssendelft, J.L., Willis, L.B., Lessard, P.A.,Ghiviriga, I., Sambandan, T.G., Rha, C.K., and Sinskey, A.J. 2006. Characterizationof Streptomyces MITKK-103, a newly isolated actinomycin X2-producer. Appl. Microbiol. Biotechnol., 72,145-154.

Lackner, H., Holsmann, H., Heinze, S., Simon, H., Bar, H., Zimmer, C., and Graphe , U. A new actinomycin-type chromopeptide from Streptomyces $s p$. HKI-0155. J. Antibiot., 53, 84-87.

Masuda, M., Abe, T., and Sato, S. 1997. Diversity of halogenated secondary metabolites in the red algae Laurencianipponcia

(RhodomelaceaeCeramiales).J. Phycol., 33: 196-208.

Newman, D.J. and Cragg, M.G. 2007. Natural products as sources of new drugs over the last years. J. Nat. Prod., 70: 461-477.

Praveen, V., Tripathi, C.K.M, Bihari, V., and Srivastava, S.C. 2008 b. Productionof actinomycin-D by the mutant of a new isolate of Streptomyces sindenensis. Braz. J. Microbiol., 39:
689-692.

Ren, J. et al. 2013.Venezuelines A-G, new phenoxazine-based alkaloids and aminophenols from Streptomyces venezuelaeand the regulation of gene target Nur 77. Bioorg. Med. chem. Lett., 23: 301-304.

Wagman, G.H., Marquez, J.A., Watkins, P.D., Gentile, F., Murawski, A., Patel, M., and Weinstein, M.J. 1976. A new actinomycin complex produced from Micromonospora species: fermentation, isolation and characterization. Antimicrob. Agents. Chemother., 11: 281-290.

Walsh, J.A. and Warren, K.S. 1974. Selective primary health care: an interim strategy for disease control in developing countries. N. Eng. J. Med., 301: 367-370.

Watve, M.G., Tickoo, R., Jog, M.M., Bhole, B.D. 2001. How many antibiotics are produced by the genus Steptomyces? Arch. Microbiol., 176: 386-390.

Wilson, A.P. 2000. Cytotoxicity and viability assays in animal cell culture. A practical approach ( $3^{\text {rd }}$ edn). Oxford Univ Press. Oxford PP, 175-21.

\section{How to cite this article:}

Cibi, R., and Jayakumaran Nair, A. 2016. Purification of Actinomycin D from Streptomyces parvulus Isolated from Mangrove Ecosystem of Kerala, India. Int.J.Curr.Microbiol.App.Sci. 5(7): 461-467. doi: http://dx.doi.org/10.20546/ijcmas.2016.507.049 